Supporting Information

\title{
Enhancing metal separations using hydrophilic ionic liquids and analogues as complexing agents in the more polar phase of liquid- liquid extraction systems
}

\author{
Zheng Li, ${ }^{* \dagger}$ Bieke Onghena,,$^{\dagger}$ Xiaohua Li, ${ }^{\dagger}$ Zidan Zhang, ${ }^{+}$Koen Binnemans ${ }^{\dagger}$
}

†Department of Chemistry, KU Leuven, Heverlee, B-3001, Belgium

Department of Chemical Engineering, University of Texas at Austin, Austin, Texas 78712, United States

Total number of pages: 7 (S1-S7)

Total number of figures: 3 (Figure S1-S3)

Total number of tables: 2 (S1-S2) 


\subsection{Mutual solubility}

In addition to the solubility of extractants, the mutual solubility of EG and $p$-cymene in the two phases was also determined (Fig. S1). With increasing C923 concentration in the LP phase, more EG was dissolved in the LP phase, increasing from $1.3 \mathrm{~g} \mathrm{~L}^{-1}$ at $0.0 \% \mathrm{C} 923$ to $143.2 \mathrm{~g} \cdot \mathrm{L}^{-1}$ at $60 \%$ C923 for the TMP containing system, and from $0.4 \mathrm{~g} \cdot \mathrm{L}^{-1}$ at $0 \mathrm{C} 923$ to $118.3 \mathrm{~g} \cdot \mathrm{L}^{-1}$ at $60 \% \mathrm{C} 923$ for the TEAC containing system. An opposite trend was observed for the solubility of $p$-cymene in the MP phase. With the increasing C923 concentration in the LP phase, $p$-cymene in the more polar phase decreased from $11.1 \mathrm{~g} \cdot \mathrm{L}^{-1}$ at $0.0 \% \mathrm{C} 923$ to $7.0 \mathrm{~g} \cdot \mathrm{L}^{-1}$ at $60 \% \mathrm{C} 923$ for the TMP containing system, and from $7.4 \mathrm{~g} / \mathrm{L}$ at $0.0 \% \mathrm{C} 923$ to $5.4 \mathrm{~g} \cdot \mathrm{L}^{-1}$ at $60 \% \mathrm{C} 923$ for the TEAC containing system. It is interesting to note that both the solubility of EG in the LP phase and $p$ cymene in the MP phase are smaller for the TEAC containing system than for the TMP containing system. This means that the high polarity of TEAC minimizes not only the mutual solubility of the two extractants in the two phases, but also the mutual solubility of the two diluents. Although EG and $p$-cymene are soluble in the opposite phase, they do not affect extraction because they are not involved in the extraction reaction.

Furthermore, the distribution of water between EG and the LP phase with various C923 was determined, shown in Figure S2. With increasing amount of C923, water content in the LP phase increased rapidly. At 60 vol\% C923, up to $7.9 \%$ water was distributed in the LP phase. This result proves that molecular compounds cannot be confined in the MP phase, even for water, which is a very polar and the smallest liquid molecular compound at room temperature.

The solubilities of other hydrophilic ILs in the LP phase were measured after equilibrating 1.0 $\mathrm{mol} \cdot \mathrm{L}^{-1}$ of each organic salt in EG with $20 \mathrm{vol} \% \mathrm{C} 923$ in $p$-cymene. No hydrophilic ILs could be detected in the LP phase, meaning that these organic salts completely resided in the MP phase.

\subsection{EXAFS}

The amplitude reduction factor $S_{0}$ for fitting the sample was first determined separately by fitting the EXAFS function of a $\left[\mathrm{Co}\left(\mathrm{H}_{2} \mathrm{O}\right)_{6}\right]^{2+}$ reference using a model consisting of one single-scattering Co-O interaction. By fixing $S_{0}$ on a physically probable value of 0.8 , a correct coordination number of the reference (5.9(5)) was achieved (Table S2, Fig S3). This $S_{0}$ value of 0.8 was subsequently used in the EXAFS function fitting of the Co(II)-complex to determine the other parameters of the two paths: the degeneracy $(N)$, the half path length $(r)$, the Debye-Waller factor $\left(\sigma^{2}\right)$ and the energy of the edge $\left(E_{0}\right)$. $E_{0}$ was constrained to be the same in both paths. 
Table S1. Errors of Co(II) and Sm(III) extraction

\begin{tabular}{|c|c|c|c|c|c|c|}
\hline \multirow{2}{*}{ TEAC(M) } & \multicolumn{7}{|c|}{ Co(II) Extraction } \\
\cline { 2 - 7 } & Test 1 & Test 2 & Test 3 & Average (\%) & STD (\%E) & Error (\%) \\
\hline 0.00 & 0.14 & 0.19 & 0.17 & 0.17 & 0.025 & 15.10 \\
\hline 0.30 & 4.31 & 3.40 & 3.85 & 3.85 & 0.46 & 11.81 \\
\hline 0.60 & 8.21 & 7.68 & 8.15 & 8.01 & 0.290 & 3.62 \\
\hline 0.90 & 15.55 & 13.29 & 13.99 & 14.28 & 1.16 & 8.10 \\
\hline 1.20 & 23.22 & 19.28 & 20.35 & 20.95 & 2.04 & 9.73 \\
\hline 1.50 & 19.57 & 21.79 & 22.35 & 21.24 & 1.47 & 6.92 \\
\hline 1.80 & 12.03 & 17.88 & 17.52 & 15.81 & 3.28 & 20.74 \\
\hline 2.10 & 8.77 & 10.97 & 11.09 & 10.28 & 1.31 & 12.7 \\
\hline 2.40 & 4.33 & 5.58 & 5.55 & 5.15 & 0.71 & 13.84 \\
\hline 2.70 & 2.15 & 2.75 & 2.73 & 2.54 & 0.34 & 13.40 \\
\hline 3.00 & 1.00 & 1.33 & 1.30 & 1.21 & 0.18 & 15.08 \\
\hline & & & & & & \\
\hline TEAC(M) & & & Sm(III) Extraction & & \\
\cline { 2 - 8 } & Test 1 & Test 2 & Test 3 & Average (\%E) & STD (\%E) & Error (\%) \\
\hline 0.00 & 2.42 & 1.96 & 2.09 & 2.16 & 0.24 & 11.00 \\
\hline 0.30 & 3.02 & 2.93 & 3.23 & 3.06 & 0.15 & 5.03 \\
\hline 0.60 & 2.63 & 4.06 & 4.43 & 3.71 & 0.95 & 25.65 \\
\hline 0.90 & 3.69 & 5.66 & 6.02 & 5.12 & 1.25 & 24.48 \\
\hline 1.20 & 7.53 & 8.19 & 8.59 & 8.10 & 0.54 & 6.61 \\
\hline 1.50 & 11.04 & 11.84 & 12.25 & 11.71 & 0.62 & 5.26 \\
\hline 1.80 & 16.35 & 17.99 & 18.19 & 17.51 & 1.01 & 5.77 \\
\hline 2.10 & 30.37 & 28.91 & 29.96 & 29.75 & 0.75 & 2.53 \\
\hline 2.40 & 50.48 & 48.35 & 47.79 & 48.87 & 1.42 & 2.90 \\
\hline 2.70 & 73.64 & 71.81 & 72.05 & 72.50 & 0.99 & 1.37 \\
\hline 3.00 & 90.16 & 89.94 & 89.46 & 89.85 & 0.36 & 0.40 \\
\hline
\end{tabular}


Table S2. EXAFS fitting results

\begin{tabular}{|c|c|c|c|c|}
\hline Sample & Interactions & $N$ & $r(\AA)$ & $\sigma^{2}\left(\AA^{2}\right)$ \\
\hline $\begin{array}{c}{\left[\mathrm{Co}\left(\mathrm{H}_{2} \mathrm{O}\right)_{6}\right]^{2+}} \\
\text { reference }\end{array}$ & $\mathrm{Co}-\mathrm{O}$ & $5.9(5)$ & $2.081(6)$ & $0.006(1)$ \\
\hline $\begin{array}{c}\mathrm{Co}^{\mathrm{II}} \text { complex in the } \\
\text { less polar phase }\end{array}$ & $\mathrm{Co}-\mathrm{O}$ & $1.5(9)$ & $2.002(3)$ & $0.002(2)$ \\
\cline { 2 - 5 } & $\mathrm{Co}-\mathrm{Cl}$ & $1.9(7)$ & $2.263(2)$ & $0.003(2)$ \\
\hline
\end{tabular}

Note: $N$ is the degeneracy, $r$ is the half path length and $\sigma^{2}$ is the Debye-Waller factor. 

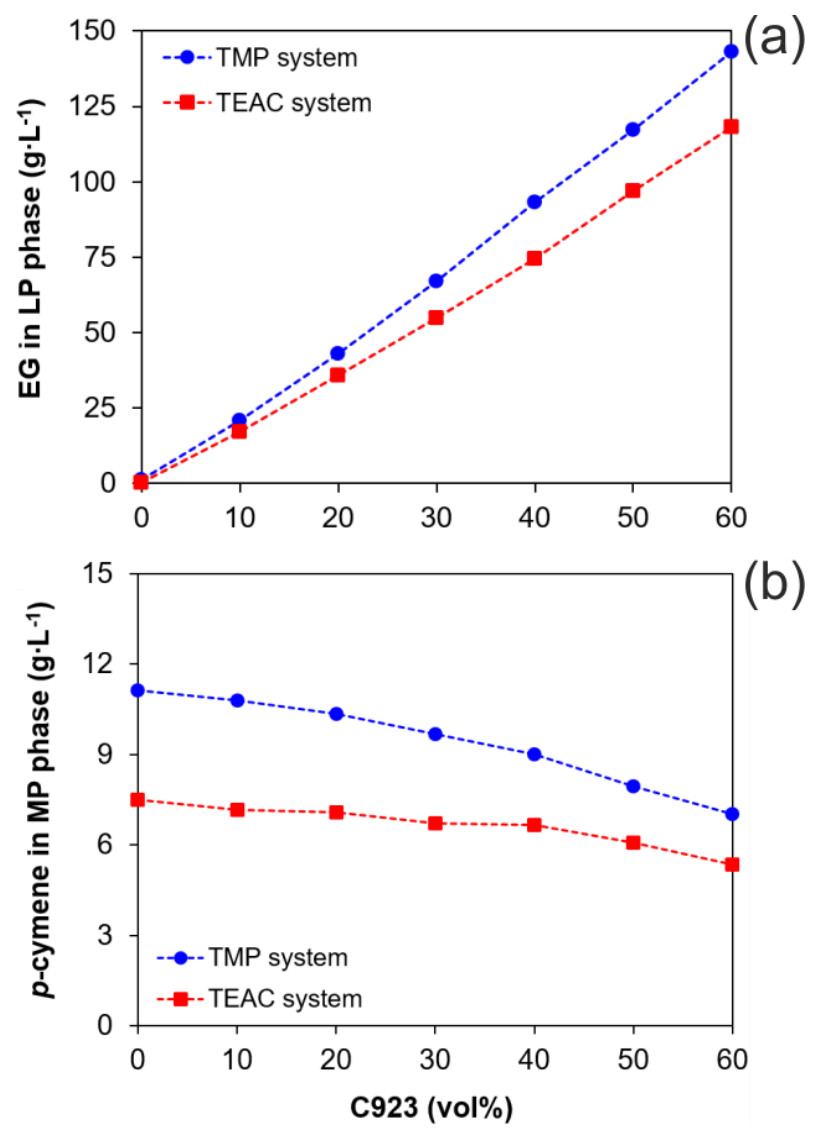

Figure. S1. Solubility of EG in the LP phase (a) and $p$-cymene in the MP phase (b). The LP phase contained 0-60 vol\% C923 in $p$-cymene, while the MP phase contained $1.0 \mathrm{~mol} \cdot \mathrm{L}^{-1}$ trimethyl phosphate (TMP) or tetraethylammonium chloride (TEAC) in EG. 


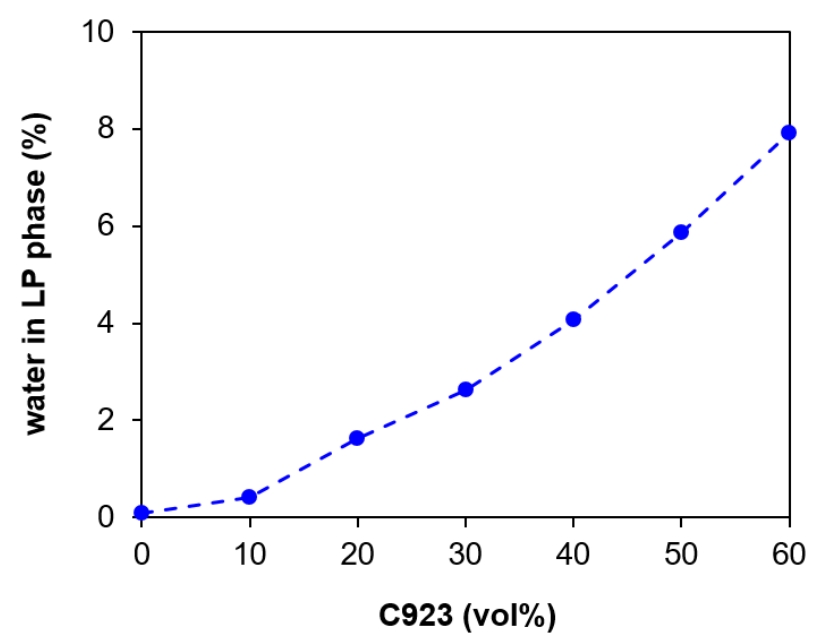

Figure. S2 Water content in the LP phase with respect to the total water amount. The LP phase contained 0-60 vol\% C923 in p-cymene, while the MP phase contained $10 \mathrm{vol} \% \mathrm{H}_{2} \mathrm{O}$ in EG. 

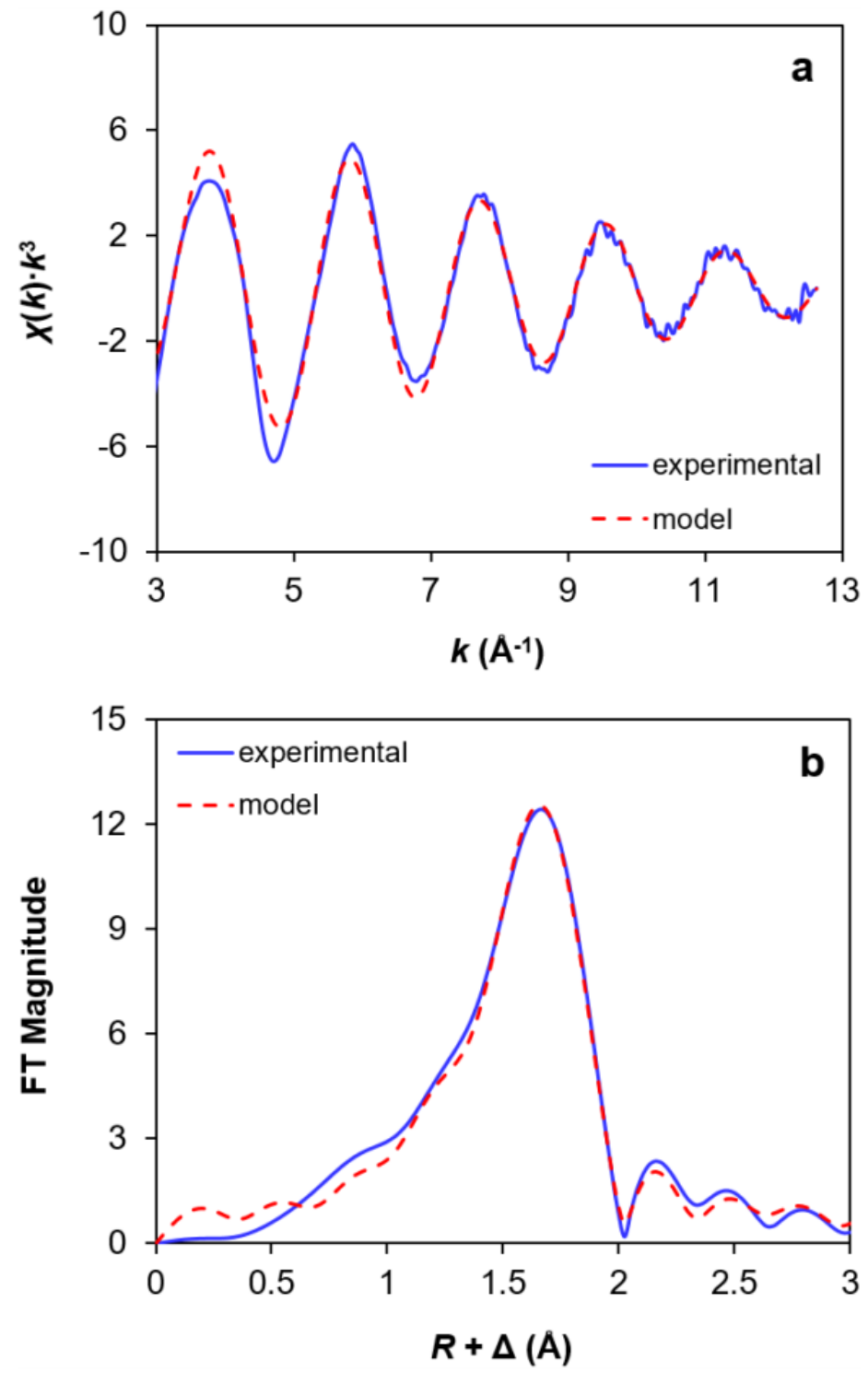

Figure S3. $k^{3}$-Weighed EXAFS function (a) and Fourier transform (b) of the $\left[\mathrm{Co}\left(\mathrm{H}_{2} \mathrm{O}\right)_{6}\right]^{2+}$ reference solution $\left(0.10 \mathrm{~mol} \cdot \mathrm{L}^{-1} \mathrm{Co}\left(\mathrm{NO}_{3}\right)_{2}\right.$ in ultrapure water $)$. 